Original Article

\title{
The portrait of neem leaves-based high performance wound healing activity on zebrafish
}

\author{
Nour Athiroh A.S ${ }^{1 *}$, Ari Hayati ${ }^{1}$, Istirochah Pudjiwati ${ }^{2}$, Ahmad Taufiq $^{3}$, Nurul Jadid Mubarakati ${ }^{1}$ \\ ${ }^{1}$ Department of Biology, Faculty of Mathematics and Natural Sciences, Universitas Islam Malang, 65144, Indonesia \\ ${ }^{2}$ Department of Agrotechnology, Faculty of Agriculture, Universitas Islam Malang, 65144, Indonesia \\ ${ }^{3}$ Department of Physics, Faculty of Mathematics and Natural Sciences, State University Malang, 65145, Indonesia
}

\section{Abstract}

This study was designed to evaluate the role of sliced and dropping models of neem leaves (Azadirachta indica) and environmental factors on zebrafish wound shrinkage. This study employed two treatment models: neem leaf slices and drops model. The treatment in the neem leaf slice model was the control group (fish was injured without neem leaf slices treatment, and G1-G3 of each fish was injured at $0.3 \mathrm{~cm}+0.5,1$, and $2 \mathrm{~g}$. Treatment in the neem leaf drop model was control group (fish was injured without neem leaves drops, and G1-G3 of each fish was injured at $0.3 \mathrm{~cm}+1$, 2, 4 drops. Findings suggest that there is a significant difference between the control group by treating G1, G2, and G3 on the shrinkage of zebrafish wound area both in the neem leaf slice and drop models, but G1 was not significantly different from G2 and G3, as well as G2 and G3 both in the neem leaf slice and drop model. Neem leaves contain nutrients that play a vital role in the formation of collagen and the formation of new capillaries to help speed up the wound healing process. The healing process involves the dynamic interaction of physiological factors.

Keywords: Drop model, leaf slice, neem, wound healing, zebrafish

Received: July 03, 2021 Revised: September 16, 2021 Accepted: September 16, 2021

\section{Introduction}

Neem plants are abundantly scattered around the coast of Bangsring Underwater (Bunder) Banyuwangi, East Java, Indonesia. These plants grow to 2-3 ha around Bunder, but fishermen or the community have not used neem to support marine biota conservation, for example, marine fish conservation. Hitherto, treatment for injured marine fish is given using chemical drugs. Chemical drugs have negative impacts on both fish and the environment. Thus, it is necessary to test the neem leaves on zebrafish on a laboratory scale. Neem leaves contain alkaloids, paraicins, tannins, flavonoids, saponins, and essential oil components that contain sulfide compounds. Neem leaves have anti-inflammatory, antibacterial, and antioxidant effects (Ouerfelli et al., 2019).

The content of flavonoids, alkaloids, and tannins in neem leaves can inhibit bacterial growth and bacterial motility as well as damage bacterial cell membranes so that bacterial cells will vanish (protein coagulator), especially in the remodeling process and inhibiting fibroblast growth, thus, wound care will be easier. In addition, tannins function as astringents that can cause shrinkage of the scale pores, harden the scales, stop light exudates and bleeding to cover wounds and prevent bleeding that usually occurs (Alzohairy, 2016). In addition, saponins are antimicrobials and can clean and serve as an antiseptic so that wounds do not experience severe infections, and saponins have a high level of

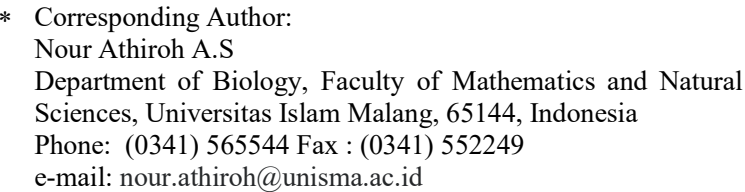

toxicity to fungi and increase collagen content and accelerate the epitalization process so that the wound healing process will be faster (Sumintarti and Jessica, 2020).

To investigate the role and efficacy of neem leaves in wound healing, an experimental study was carried out using injured zebrafish. The major steps and principles of cutaneous wound healing are conserved among adult mammals and adult zebrafish, making zebrafish a valuable model for studying vertebrate skin repair $(\mathrm{Li}$ and Uitto, 2014). Our objective was to evaluate the role of the sliced and dropping model of neem (Azadirachta indica) leaves and environmental factors on zebrafish wound shrinkage so that it acts as an antiseptic for aquatic biota.

\section{Methods}

The experimental model of research

This study employed an experimental laboratory method using a post-test-only-control-group design (Mutia., 2018). The study has received ethical clearance from the Health Research Ethics Committee of the Faculty of Medicine, University of Islam Malang (number:004/LE.001/IV/01/2020). The experimental model is presented in (Table 1).

In this study, the aquarium was washed using warm water and sterilized using alcohol. The aquarium was filled with $20 \mathrm{~L}$ of distilled water and labeled according to treatment. An aerator was prepared and installed in an aquarium with an aqueduct to supply oxygen. The criteria for inclusion namely zebrafish (Danio rerio) male and female have an average life of 118 the day (3-6 months), size 1-1.5 inches, healthy fish based on physical state and the activity of swim. One of the advantages of 
the zebrafish model system is a freshwater vertebrate with a complement of genes very similar to those of mammals. Furthermore, zebrafish were put in the aquarium, acclimatized for 2-3 h. The zebrafish were given pellets two times a day: morning and evening. Each aquarium was filled with seven zebrafish and equipped with mechanical and biological filters arranged in a series model. Each aquarium was also given live plants to supply oxygen. The optimal temperature required for fish in the aquarium was kept within the normal range of $22-27{ }^{\circ} \mathrm{C}$. Water change and $\mathrm{pH}$ tests were carried out once a week, and freshwater $\mathrm{pH}$ remains in the range of 6.6-7.8 (Marimuthu et al., 2019).

\section{Procedure of injuring zebrafish (Danio rerio)}

The treatment in the neem leaf slice model was the control group (fish was injured without neem leaf slices treatment, and G1-G3 of each fish was injured at $0.3 \mathrm{~cm}$ $+0.5,1$, and $2 \mathrm{~g}$. Treatments in the neem leaf drop model was control group (fish was injured without neem leaves drops, and G1-G3 of each fish was injured at $0.3 \mathrm{~cm}+1$, 2, 4 drops.
The fish were injured on the lateral line $0.3 \mathrm{~cm}$ long, employing a surgical cutter that had been sterilized using $70 \%$ alcohol. While injured, the fish were still placed in the aquarium water treated with neem leaves. The leaves used were old, clean, and unrotten. The leaves were washed clean. The washed leaves were then weighed and chopped into small pieces and weighed at $0.5,1$, and $2 \mathrm{~g}$. These leaves were sprinkled into the aquarium water according to model 1 . In the model 2 treatment, neem leaves were weighed at $1 \mathrm{~g}$ with mortar then added $10 \mathrm{cc}$ of water.

The leaves were then squeezed until the liquid was obtained to be dripped into the fish wound. The fluidmaking process was carried out every day. The injured fish have 1 drop, 2 drops, and 4 drops of leaf liquid every day for 7 days, according to model 2. Abiotic environmental measurements included $\mathrm{pH}$ and aquarium temperature measurements that were carried out every day for up to 7 days. In the analysis, we employed ANOVA calculation. The mechanism of wound healing in this study is presented in Figure 1.

Table 1. The experimental model of research

\begin{tabular}{cll}
\hline Treatment & Neem Leaf Slices (Model 1) & Neem Leaf Drops (Model 2) \\
\hline Control & $\begin{array}{l}\text { Control (fish was injured without being given neem } \\
\text { leaves) }\end{array}$ & $\begin{array}{l}\text { Control (fish was injured without being given neem } \\
\text { leaf drops) }\end{array}$ \\
Group 1 & Fish injured at $1 \mathrm{~cm}+0.5 \mathrm{~g}$ & Fish injured at $1 \mathrm{~cm}+1 \mathrm{drop}$ \\
Group 2 & Fish injured at $1 \mathrm{~cm}+1 \mathrm{~g}$ & Fish injured at $1 \mathrm{~cm}+2 \mathrm{drops}$ \\
Group 3 & Fish injured at $1 \mathrm{~cm}+2 \mathrm{~g}$ & Fish injured at $1 \mathrm{~cm}+4 \mathrm{drops}$ \\
\hline
\end{tabular}

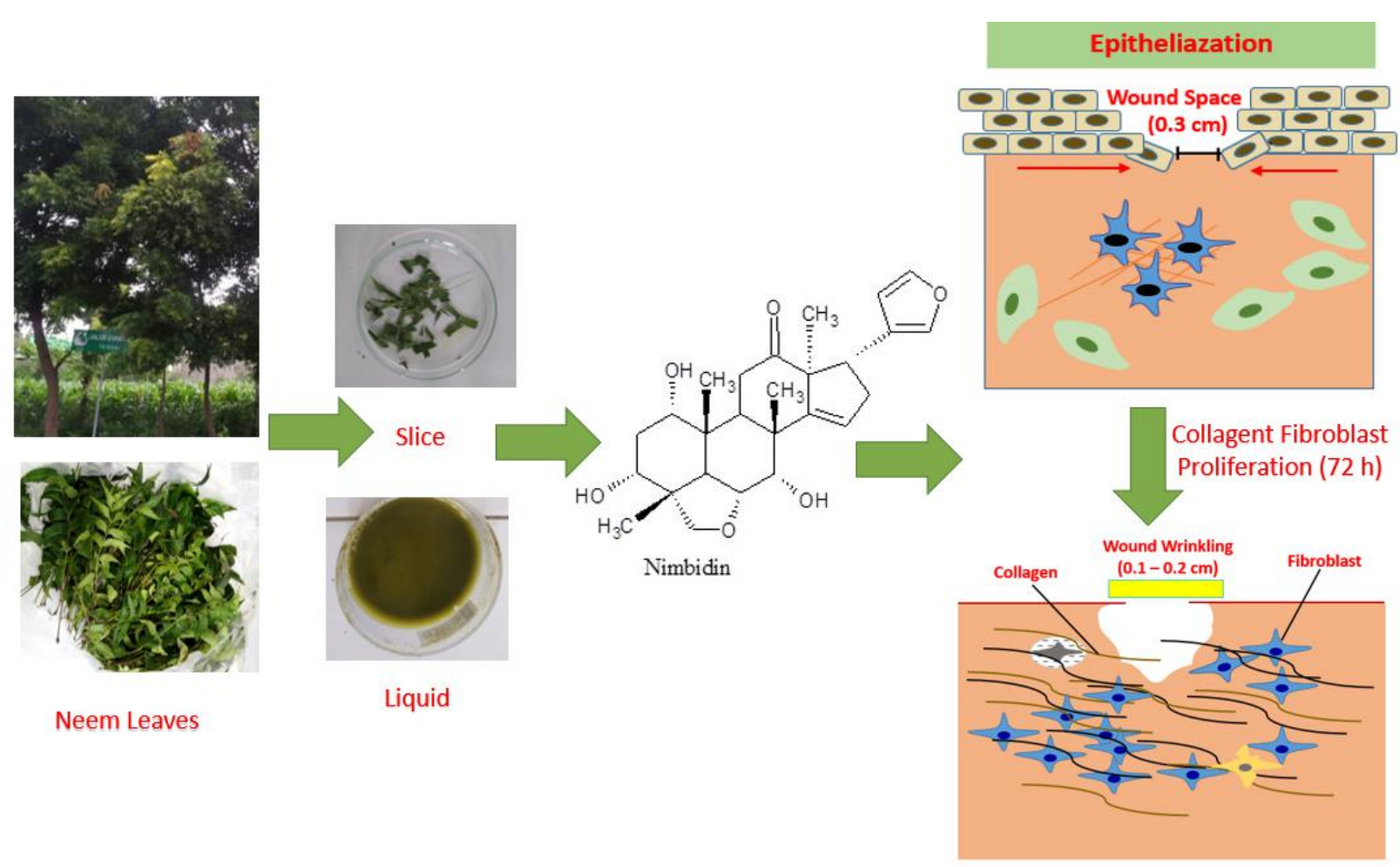

Figure 1. The mechanism of wound healing process in zebra fish by the treatment of neem leaves extraction 


\section{Results}

In this study, efficacy of neem leaves in wound healing using injured zebrafish, were investigated. The role of the sliced and dropping model of neem (Azadirachta indica) leaves and environmental factors on zebrafish wound shrinkage acts as an antiseptic for aquatic biota are presented in Table 2, Table 3 and Table 4. This shows that there is a significant difference ( $p$ $<0.05$ ) between control and treatment G1, G2, and G3 on the shrinkage of the zebrafish wound area. The test was continued using Tukey's Post Hoc, which indicates that there was a significant difference between control and G1 treatment $(p<.01)$, and there was a significant difference between G2 and G3 $(p<.001)$. There is no real difference between G1, G2, and G3 as well as G2 and G3 (Table 2).

This study also confirmed the abiotic environment for experimental animals. Table 3 and Table 4 showed that data on abiotic factors in measuring $\mathrm{pH}$ and temperature were not significantly different in all treatments. Thus environmental factors were stable.

\section{Discussion}

Neem leaves cause wound shrinkage in zebrafish as there are active substances that can shrink the wound.
The wound healing process involves the dynamic interaction of physiological factors consisting of four general phases: hemostasis, inflammation, proliferation, and remodeling (Dan et al., 2018; Dorantes and Mara, 2019). Wound healing always begins with blood clotting as the first thing to close the wound. Platelet activation during hemostasis releases a number of important cytokines that initiate the healing process through chemotactic signals directed to inflammatory and resident cells. In addition, the fibrin fibronectin clot acts as a provisional matrix of epithelial cells and fibroblasts to be able to migrate to the wound area. The release of cytokines during the clotting phase initiates the inflammatory reaction to provide debridement by removing damaged tissue and microbes. During the process of this innate immune response, inflammatory cells that have been recruited in the wound area will release more cytokines and chemokines, which function to modulate wound healing. Macrophages are the most important cells in wound repair. Macrophage cells secrete vascular endothelial growth factor (VEGF), Fibroblasts growth factor (FGF), and Transforming growth factor (TGFB) are the most significant regulators for tissue repair (Coskun et al., 2007).

$\underline{\text { Table 2. Shrinking of Zebrafish after Slicing and Drops of Neem Leaves }}$

\begin{tabular}{lll}
\hline Treatment & Neem Leaf Slices (Model 1) & Neem Leaf Drops (Model 2) \\
\hline Control & $0.286 \pm 0.0378^{\mathrm{a}}$ & $0.286 \pm 0.0378^{\mathrm{a}}$ \\
Group 1 & $0.157 \pm 0.0787^{\mathrm{b}}$ & $0.200 \pm 0.0577^{\mathrm{b}}$ \\
Group 2 & $0.129 \pm 0.0756^{\mathrm{b}}$ & $0.157 \pm 0.0535^{\mathrm{b}}$ \\
Group 3 & $0.114 \pm 0.0378^{\mathrm{b}}$ & $0.143 \pm 0.0535^{\mathrm{b}}$ \\
\hline
\end{tabular}

Note: the same notation indicates not real difference and different notations indicate its difference.

Macroscopic examination on day 7 showed that the wound treated with neem leaf extract appeared to be fused, smaller, and there was a crust covering the wound healing process. Meanwhile, the wounds on zebrafish that were not given neem leaves appeared that the wounds had not been evenly fused, were longer, shriveled, and had not covered with crust in some parts. On day 7, a proliferation phase, basic substance, collagen fibers, and new blood vessels begin to infiltrate the wound. After collagen is formed, there is an increase in wound shrinkage. At this point, the remodeling phase occurs, and the collagen formed will fuse, pressing the blood vessels in healing the wound so that the scar becomes even and thin.

The development of a traditional medicinal plant such as neem leaves has been directed for modern medicine. The strong antibacterial activity against bacterial strains suggests that traditional plants can be used as a treatment for wound-causing bacteria and viruses (Taye et al., 2011; Avdesh et al., 2012). Previous studies have shown that the extracts of neem bark and leaves have been tested against the presence of 105 bacterial strains from seven genera, namely Enterococcus, Salmonella, Staphylococcus, Pseudomonas, Escherichia, Klebsiella, and Mycobacterium (Paul et al., 2011). The healing mechanism for burns of betel nut extract can occur due to the presence of tannin compounds that function as antibacterial, antifungal, and adstringent, which causes the reduction of skin pores, hardens the skin, and stops light bleeding.

Chemical content produced by Bixa orellana in water and ethanol extracts are alkaloids, tannins, triterpenoids, steroids, and flavonoids. These compounds have a mechanism that helps in the healing process of burns (Espiritu et al., 2016). The flavonoids contained in sweet potato leaves can be used as a prevention against wound infection because they have antiseptic properties. Herbal plants that have the potential for wound healing are areca nuts, Anredera cordifolia leaves, avocado leaves, guava leaves, Pilea melastomoides leaves, sweet potato leaves, Uncaria sp leaves, Jatropha curcas leaves, and mangosteen that generally contain flavonoids, saponins, and tannins. Gynura divaricata leaves that can act as an antiseptic and accelerate wound healing include flavonoids, saponins, tannins, and essential oils. Besides being effective as an antiseptic and accelerating wound healing, G. divaricata leaves can also reduce blood glucose levels, lower blood cholesterol levels, relieve joint pain due to gout, and serve as an antipyretic. The use of medicinal plants is generally safer (Seo et al., 2017).

The results of statistical analysis of $\mathrm{pH}$ and temperature measurements in aquarium water between 
treatments were not significantly different (Table 3 and Table 4). This indicates that the laboratory environment is stable (Miller et al., 2018). There was a tendency for the $\mathrm{pH}$ to decrease in the neem leaf treatment compared to the control group. The decrease in $\mathrm{pH}$ is caused by the presence of bioactive tannin compounds. Neem leaves have been shown to contain flavonoids, alkaloids, and tannins which have antibacterial and antiseptic effects (Ribas and Francesc, 2014; Ouerfelli et al., 2019). Meanwhile, the neem tree contains various phytochemical compounds such as alkaloids, triterpenoids, and glycosides, limonoids, flavonoids, fatty acids, and steroids and are proven to have antiinflammatory, anti-carcinogenic, antiulcer, antioxidant, immunomodulatory, antifungal, antibacterial, antiviral, antimalarial, antimutagenic properties, and antihyperglycemic properties (Al AlSheikh et al., 2020). In general, tannins are soluble in water. Tannin has general properties, namely having a phenol group and colloidal properties so that if dissolved in water, it is a colloidal and weak acid. This resulted in the aquarium water in the neem treatment group being more acidic than the aquarium water in the control group. Pure tannins are acidic as pure water solvents produce a $\mathrm{pH}$ below 7. It occurs since the phenol groups' cause the tannins in water to be acidic (Wang et al., 2018).

Tannins are polyphenolic aromatic compounds that have a cool feeling and can tan the skin, have an amortic shape, have a light mass, have a very sharp and specific taste, precipitate alkaloids, and glycosides from solutions.
Tannins are phenolic compounds that have a large molecular weight consisting of a hydroxy group and several related groups such as carboxyls to form effectively strong complexes with proteins and some macromolecules (Ashok and Kumud, 2012). Tannins are divided into two types: condensed tannins and hydrolyzed tannins. Condensed tannins occur due to polymerization (condensation) reactions between flavonoids, while hydrolyzed tannins are formed from esterification reactions of phenolic acids and sugars (glucose). Tannins are easily oxidized. These tannins made the aquarium water in the treatment group more acidic than the control group. Thus, neem leaves act as ethnomedicine and function to reduce wrinkles in wounds (Athiroh et al., 2020)

The findings of this study was found that neem leaves were able to shrink wounds in zebrafish. Sliced neem leaves have more potential to shrink wounds than neem drops. An active substance in a leaf slices a lot more than leaf drops. Sliced leaves had a very significant effect on moisture content, ash content, bioactive total (Menkes, 2017). Neem leaves play an essential role in collagen formation and new capillaries formation to speed up the wound healing process. Furthermore, neem leaves lower the $\mathrm{pH}$ of the aquarium water. Interestingly, the dynamic interaction of physiological factors consisting of four general phases such as hemostasis, inflammation, proliferation, and remodeling was involved in the healing process.

Table 3. Abiotic factor measurement in model 1

\begin{tabular}{lcc}
\hline \multirow{2}{*}{ Treatment } & \multicolumn{2}{c}{ Abiotic Factor } \\
\cline { 2 - 3 } & $\mathrm{pH}$ & Temperature $\left({ }^{\circ} \mathrm{C}\right)$ \\
\hline Control & $8.42 \pm 0.1199^{\mathrm{a}}$ & $25.6 \pm 0.768^{\mathrm{a}}$ \\
$\mathrm{G} 1+0.5 \mathrm{~g}$ & $8.33 \pm 0.1430^{\mathrm{a}}$ & $25.4 \pm 0.749^{\mathrm{a}}$ \\
$\mathrm{G} 2+1 \mathrm{~g}$ & $8.36 \pm 0.0721^{\mathrm{a}}$ & $25.1 \pm 0.734^{\mathrm{a}}$ \\
$\mathrm{G} 3+2 \mathrm{~g}$ & $8.39 \pm 0.0469^{\mathrm{a}}$ & $24.9 \pm 0.697^{\mathrm{a}}$ \\
\hline
\end{tabular}

Note: the same notation indicates no significant difference

Table 4. Abiotic factor measurement in model 2

\begin{tabular}{lcc}
\hline Treatment & $\mathrm{pH}$ & Abiotic Factor \\
\cline { 2 - 3 } Control & $8.44 \pm 0.0886^{\mathrm{a}}$ & Temperature $\left({ }^{\circ} \mathrm{C}\right)$ \\
$\mathrm{G} 1+1$ drop & $8.40 \pm 0.0743^{\mathrm{a}}$ & $24.7 \pm 0.658^{\mathrm{a}}$ \\
$\mathrm{G} 2+2$ drops & $8.43 \pm 0.0723^{\mathrm{a}}$ & $24.7 \pm 0.582^{\mathrm{a}}$ \\
$\mathrm{G} 3+4$ drops & $8.44 \pm 0.0667^{\mathrm{a}}$ & $24.5 \pm 0.597^{\mathrm{a}}$ \\
\hline Note: the same notation indicates no significant difference $\mathrm{pH}$ and temperature measurements were not significantly different in all treatments
\end{tabular}

\section{Acknowledgment}

This work was supported by The Ministry of Research, Technology, and Higher Education for funding this work through Penelitian Dasar Unggulan Perguruan Tinggi (PDUPT) 2020 with contract number: 187/SP2H/LT/DRPM/2020/9 March 2020; 017/SP2H/LT- MULTI/LL7/2020/7 March 2020; 194/g164/U.LPPM/K/B.07/VIII/2020/7 August 2020.

\section{References}

Alzohairy, M.A. (2016). Therapeutics role of Azadirachta indica (Neem) and their active constituents in diseases prevention and treatment. Evidence-Based Complementary and Alternative Medicine, 2016, 1-12.

Al AlSheikh, H.M., Insha, S., Vijay, K., Irfan, A.R., Hashem, A., Arif, T.J., \& Qazi, M.R.H. (2020). Plant-based phytochemicals as possible alternative to antibiotics in combating bacterial drug resistance. Journal of Antibiotics, 9(8), 480.

Ashok, P.K, \& Kumud, U. (2012). Tannins are astringent. Journal of Pharmacognosy and Phytochemistry, 1(3), 45-50.

Athiroh, N., Istirochah, P., \& Ari, H. (2020). Proceedings of international conference on applied sciences, Information and Technology 2020, 1-3 November 2020, Padang, Indonesia

Avdesh, A., Mengqi, C., Mathew, T.M., Alinda, M., Daniel, O., Stephanie, R., Kevin, T., Michael, L., David, M.G., Giuseppe, V., \& Ralph, N.M. (2012). Regular care and maintenance of a Zebrafish (Danio rerio) laboratory: an introduction. Journal of visualized experiments, $18(69), 4196$.

Coskun, S., Emine, G.G., \& Barbaros, B. (2007). Effects of epidermal growth factor on lipid peroxidation and nitric oxide levels in 
oral mucosal ulcer healing: a time-course study. Surgery Today, 37(7), 570-4.

Dan, M.M., Sarmah, P., Dhilleswara,, R.V., \& Dattatreya, A. (2018). Wound healing: concepts and updates in herbal medicine. International Journal of Medical Research \& Health Sciences, 7(1), 170-181.

Dorantes, L.C \& Mara, C.A. (2019). Skin acute wound healing: a comprehensive review. International Journal of Inflammation, 2019, 1-15.

Espiritu, A.A., Shaira, N.L.L, \& Jonathan J.G.G. (2016). Burn wound healing potential of Bixa orellana Linn [Bixaceae] leaf extracts on albino mice. Journal of Medicinal Plants Studies, 4(1), 84-87.

Li, Q., \& Uitto, J. (2014). Zebrafish as a model system to study skin biology and pathology. Journal of Investigative Dermatology 134, e21.

Marimuthu, K., Palaniandy, H., \& Muchlisi, Z.A. (2019). Effect of different water ph on hatching and survival rates of african catfish Clarias gariepinus (Pisces: Clariidae). Aceh Journal of Animal Science, 4(2), 80-88.

Menkes, 2017. Formularium ramuan obat tradisional indonesia, http://hukor.kemkes.go.id. Accessed date : Augt 2021

Miller T.H., Nicolas R.B., Stewart F.O., James I.M., Leon P.B. (2018). A review of the pharmaceutical exposome in aquatic fauna. Journal of Environmental Pollution, 239, 129-146.
Mutia, A. (2018). Effect of giving fermented liquid Areca cathecu L. and surian leaves (Toona sinensis ROXB.) on tilapia wounds (Oreochromis niloticus L.). Serambi Biologi, 15(1), 48-49.

Ouerfelli, M., Juliana, V., Leila, B.B.K., \& María, P.A. (2019). Effect of neem (Azadirachta indica L.) on lipid oxidation in raw chilled beef patties. Antioxidants, 8(8), 305.

Paul, R., Murari, P., \& Nand, K.S. (2011). Anticancer biology of Azadirachta indica L (neem): A mini review. Cancer Biology \& Therapy, 12(6), 467-76.

Ribas, L., \& Francesc, P. (2014). The zebrafish (Danio rerio) as a Model Organism, with emphasis on applications for finfish aquaculture. Reviews in Aquaculture, 5(4), 209-240.

Sumintarti \& Jessica, J. (2020). Effect of cats tail leaves extract (Acalypha hispida Burm. F.) on wound healing (traumatic ulcer) of wistar male rat oral mucosa (Rattus norvegicus). Journal of Dentomaxillofacial Science, 5(1), 56-61.

Taye, B., Mirutse, G., Abebe, A., \& Jemal, S. (2011). Antibacterial activities of selected medicinal plants in traditional treatment of human wounds in Ethiopia. Asian Pacific Journal of Tropical Biomedicine, 1(5), 370-5.

Wang, P.H., Ben-Shian, H., Huann-Cheng, H., Chang-Ching, \& Y., YiJen, C. (2018). Wound healing. Journal of the Chinese Medical Association, 81(2), 94-101. 